\title{
Energy and Exergy Viability Analysis of Nanofluids As A Coolant for Microchannel Heat Sink
}

\author{
S. Mukherjee ${ }^{1}$, P. C. Mishra ${ }^{1, *}$ and P. Chaudhuri ${ }^{2,3}$ \\ ${ }^{1}$ School of Mechanical Engineering, Kalinga Institute of Industrial Technology, \\ Bhubaneswar, Odisha, India \\ ${ }^{2}$ Institute for Plasma Research, Gandhinagar, Gujarat, India \\ *Email: pcmishrafme@kiit.ac.in \\ Phone: +916746540805 \\ ${ }^{3}$ Homi Bhabha National Institute (HBNI), Anushaktinagar, Mumbai, 400094, India
}

\begin{abstract}
The present paper aims to provide a theoretical analysis of energy, exergy loss and pumping power demand of water-based $\mathrm{Al}_{2} \mathrm{O}_{3}, \mathrm{TiO}_{2}, \mathrm{CuO}, \mathrm{SiC}$ nanofluids flow through rectangular microchannel heat sinks under constant heat flux condition. The weight fraction of nanoparticles was varied from $0 \%$ to $5 \%$. Thermal resistance decreased with particle inclusion in the base fluid. Decease in thermal resistance and increase in microchannel efficiency was observed with the application of nanofluids. However, reduction in thermal resistance and rise in efficiency is more with $\mathrm{Al}_{2} \mathrm{O}_{3}$-water and $\mathrm{CuO}$ water nanofluids rather than $\mathrm{TiO}_{2}$-water and $\mathrm{SiC}$-water nanofluids. Addition of nanoparticles in base fluids was found suitable for reducing thermal resistance and increasing efficiency of microchannel but at the same time, an increase in pumping power with the rise in weight fraction was also observed. The maximum reduction in thermal resistance with a simultaneous increase in thermal efficiency was observed using $\mathrm{CuO}$ water nanofluids at $5 \% \mathrm{wt}$. fraction. The estimated exergy loss is relatively higher in $\mathrm{CuO}-$ water and $\mathrm{Al}_{2} \mathrm{O}_{3}$-water nanofluids than $\mathrm{TiO}_{2}$-water and $\mathrm{SiC}$-water nanofluids. The rise in ambient temperature effectively reduces the exergy loss. Maximum exergy loss was obtained with $\mathrm{CuO}$ nanofluids at $5 \%$ wt. fraction while the minimum was observed with water. The effect of substrate thickness on efficiency and exergy loss was also estimated.
\end{abstract}

Keywords: Nanofluids; microchannel; heat sinks; energy; efficiency; pumping power.

\section{NOMENCLATURE}

$\begin{array}{ll}A_{c h} & \text { channel area } \\ A_{\text {base }} & \text { channel base area } \\ \mathrm{C} & \text { specific heat } \\ \mathrm{d}_{\mathrm{h}} & \text { hydraulic diameter of the flow } \\ \mathrm{f} & \text { friction factor } \\ \mathrm{H}_{\mathrm{ch}} & \text { channel height } \\ \mathrm{h} & \text { heat transfer coefficient } \\ \mathrm{k} & \text { thermal conductivity } \\ \mathrm{t}_{\text {base }} & \text { base thickness } \\ \mathrm{T} & \text { temperature }\end{array}$

$\begin{array}{ll}\begin{array}{l}\text { Subscript } \\ \text { Base }\end{array} & \begin{array}{l}\text { the lower portion of the } \\ \text { foundation } \\ \text { greater amount } \\ \text { bulk }\end{array} \\ \text { bf } & \text { base fluid } \\ \text { ch } & \text { channel } \\ \text { fin } & \text { heat transfer device } \\ \text { conv } & \text { convection } \\ \text { chip } & \text { small electronic material } \\ \text { in } & \text { inlet } \\ \text { Loss } & \text { property loss in a process }\end{array}$




\begin{tabular}{llll}
$\mathrm{u}$ & flow velocity & $\mathrm{Nf}$ & nanofluids \\
$\mathrm{W}_{\mathrm{ch}}$ & channel width & $\mathrm{Np}$ & nanoparticles \\
$\mathrm{L}_{\mathrm{ch}}$ & channel length & $\mathrm{Out}$ & outlet \\
$\cdot$ & mass flow rate & $\mathrm{O}$ & ambient \\
$\mathrm{m}$ & & \multicolumn{2}{c}{ Greek symbol } \\
$\mathrm{Nu}$ & Nusselt number & $\Delta$ & difference or change \\
$\mathrm{n}$ & number of channels & $\phi$ & nanoparticle weight fraction \\
$\mathrm{p}$ & pressure & $\eta$ & efficiency \\
$\mathrm{q}$ & heat flux & $\mu$ & viscosity \\
$\mathrm{Re}$ & Reynolds number & $\rho$ & density \\
$\mathrm{R}$ & thermal resistance & & \\
$\mathrm{W}_{\text {fin }}$ & fin width & & \\
$\mathrm{X}$ & exergy & & \\
$\mathrm{v}$ & volumetric flow rate & &
\end{tabular}

\section{INTRODUCTION}

In today's world, electronic equipment encounters high heat flux with a constant demand for rapid cooling technology. Before development of an appropriate cooling facility for such devices, it is essential to estimate some important parameters such as thermal resistance, heat transfer, efficiency, pumping power etc. In this manner, a careful analysis is important before the practical application.

Tuckerman et al.[1] were first who analysed and proposed water-cooled heat sink for integrated circuits. They reported that under laminar flow condition heat transfer coefficient is inversely proportional to channel width, indicating the attractive quality of microchannel. They watched the power dissipation of $790 \mathrm{~W} / \mathrm{cm}^{2}$ for $1 \mathrm{~cm}^{2}$ area at $1^{\circ} \mathrm{C} / \mathrm{W}$ of thermal resistance, although a pressure reduction of 2 bar was monitored.

The development of the concept of "nanofluids" by Choi et al. [2], has brought a revolution in ultrafast cooling solution. Nanofluids which is an engineered colloidal dispersion of nanosized metallic (.Al, $\mathrm{Cu}$ etc.) and their oxides $\left(\mathrm{Al}_{2} \mathrm{O}_{3}, \mathrm{CuO}, \mathrm{TiO}_{2}\right.$ etc.) in traditional base fluids (water, glycol, oil etc.) enhances the heat transfer capability of base fluids by increasing their thermal conductivity.

Researcher round the globe conducted an extensive investigation on heat transfer performance in nanofluids and compared their results with the performance of traditional coolants like water, ethylene glycol etc. Chein et al. [3] introduced $\mathrm{Cu}$-water nanofluid in silicon made microchannel heat sinks. They observed an immense improvement in heat sink performance as a result of the rapid increase in thermal conductivity and thermal dispersion effect. Sohel et al. [4] investigated the heat transfer augmentation in a minichannel heat sink applying $\mathrm{Al}_{2} \mathrm{O}_{3}$-water nanofluid. They reported an improvement in heat transfer coefficient up to $18 \%$.Abdollahi et al. [5] numerically analysed the flow and heat transfer characteristics of nanofluids in microchannel heat sinks with V-type inlet/outlet arrangement under laminar flow condition. They used water-based $\mathrm{Al}_{2} \mathrm{O}_{3}$, $\mathrm{ZnO}$, and $\mathrm{SiO}_{2}, \mathrm{CuO}$ nanofluids at $1 \%, 1.5 \%$ and $2 \%$ volume fractions with three distinctive sizes of $30 \mathrm{~nm}, 40 \mathrm{~nm}$ and $60 \mathrm{~nm}$ nanoparticles in their study. They observed that heat transfer enhancement occurred in the microchannel by increasing particle inclusion and decreasing particle size simultaneously. Moreover, no vital change was observed in pressure drop characteristics.

Farsad et al.[6] compared the thermal performance of water cooled copper heat sink with the same heat sink cooled by $\mathrm{Al}_{2} \mathrm{O}_{3}$-water nanofluid and noticed a $4.5 \%$ 
improvement of cooling performance once nanofluid is employed. Bhattacharya et al.[7] numerically investigated the performance of rectangular microchannel heat sinks flooded with $\mathrm{Al}_{2} \mathrm{O}_{3}$ nanofluid and found that the thermal resistance decreased considerably with the application of nanofluid. Mohammed et al.[8] found rise in heat transfer coefficient and wall shear stress with concurrent decrease in thermal resistance when they performed a numerical study on the behaviour of heat transfer and fluid flow in rectangular microchannel heat sinks using $\mathrm{Al}_{2} \mathrm{O}_{3}$ - water nanofluid flow with volume fraction varying from $1 \%$ to $5 \%$ under laminar flow and extreme heat flux conditions. They detected a slight increase in pressure drop across the microchannel heat sink as compared to water-cooled heat sinks. Ho et al. [9] calculated the friction factor and pumping power in a microchannel heat sink and reported a minor rise in friction factor when nanofluid is used as a coolant. A lot of studies associated with the cooling performance of microchannel heat sinks with nanofluid may also be found within the numerous literature [10-13].

The previous paragraphs reveal that the majority of the studies are targeted to the heat transfer and cooling performance analysis of microchannel heat sinks. However, this trend of research unable to provide any information about energy consumption, its correct utilisation or recovering heat loss. Therefore, exergy analysis has become a prime area of research leading to improve the actual performance of the system by improving energy efficiency and minimisation of losses.

Few researchers tried to analyse the energy and exergy of microchannel heat sinks in terms of entropy generation. The decrease in exergy is proportional to the increase in entropy generation. Li et al. [14] examined the thermal performance of base fluid such as water and $\mathrm{EG}$ as well as various nanofluids like $\mathrm{Al}_{2} \mathrm{O}_{3}$-water and $\mathrm{ZnO}-\mathrm{EG}$ as coolants. The researchers illustrated that local and volumetric entropy rates caused by frictional and thermal influences for various coolants, geometries, and operational parameters. Singh et al.[15] provided a theoretical realisation of the entropy generation analysis owing to heat transfer and flow in nanofluids. They considered $\mathrm{Al}_{2} \mathrm{O}_{3}$-water nanofluids as a cooling medium. They took three different tubes of conventional, mini and micro dimensions. They observed highly viscous $\mathrm{Al}_{2} \mathrm{O}_{3}$-water nanofluids were a better coolant for minichannel and conventional channels under laminar flow and microchannel and minichannel under turbulent flow. They advised using low viscosity alumina-water nanofluids in a microchannel under laminar flow condition. They noticed that irreversibility due to flow was more significant at lower tube diameter, and thermal irreversibility was dominant at higher tube diameter. Therefore, a channel with an optimum diameter is needed to minimise the entropy generation rate for a given nanofluid for both laminar and turbulent flows. With the help of computer-generated model, Li et al. [16] analysed entropy generation in a trapezoidal microchannel under steady laminar flow using pure water and $\mathrm{CuO}$-water nanofluids. They calculated the local and volumetric entropy rates because of Reynolds numbers, channel area, inlet temperatures, frictional and thermal effects for various coolants. They suggested an optimal Reynolds number range for operating the system influenced by the attribute of the two different entropy sources, both associated with the Reynolds number. Moreover, engaging nanofluids, made with highly conductive nanoparticles at very low volume fractions could further minimise entropy generation rate owing to their superior thermal properties. Finally, they recommended choosing microchannel geometries based on minimisation of total entropy generation, subject to encounter thermal and hydraulic boundary conditions.

Khaleduzzaman et al.[17] theoretically analysed exergy and friction factor of nanofluids as a coolant for electronic devices. They used $\mathrm{Al}_{2} \mathrm{O}_{3}$-water, $\mathrm{CuO}$-water and $\mathrm{TiO}_{2}$-water nanofluids with $0.4-2 \%$ of volume fraction. The thermal resistance decreased 
whereas the energy efficiency increases with particle inclusion. The maximum efficiency of $98.9 \%$ was obtained with $\mathrm{CuO}$-water nanofluids. The exergy loss was found to be increased as the nanoparticles volume fraction is increased. The friction factor was reduced as the particle concentration of nanofluids increased. Additionally, pumping power also rose up because of the increased mass flow rate. The other reports on energy and exergy analysis can be found in the references.

In the previous part, a brief literature review has been presented showing the various different studies related to evaluate the performance microchannel heat sinks by allowing different nanofluids flow through it. $\mathrm{Al}_{2} \mathrm{O}_{3}$ and $\mathrm{CuO}$ were used as coolant extensively, but the application of other nanofluids remains neglected. Effects of particle concentration on thermal resistance, energy efficiency, exergy loss, friction factor, pressure reduction and pumping power have been studied. Effect of mass flow rate on thermal resistance and pumping power was also analysed. Although the impart of ambient temperature, a number of micro channels and substrate thickness on the energy and exergy loss has not been reported extensively. This current paper aims to evaluate the thermal resistance, pumping power, efficiency and exergy loss $\mathrm{Al}_{2} \mathrm{O}_{3}$-water, $\mathrm{CuO}$-water, $\mathrm{TIO}_{2}$-water and $\mathrm{SiC}$-water nanofluids flowing through a rectangular microchannel heat sink indicating a suitable heat sink and nanofluids combination to minimise exergy loss.

\section{THEORY AND MODELLING}

\section{Modelling of Microchannel Heat Sink}

In this present work, a rectangular heat sink working under a constant heat flux at the bottom is considered. Figure1 shows the schematic of the microchannel heat sink system considered in the analysis. The geometrical dimensions and thermal properties of the rectangular heat sink are tabulated in Table 1.

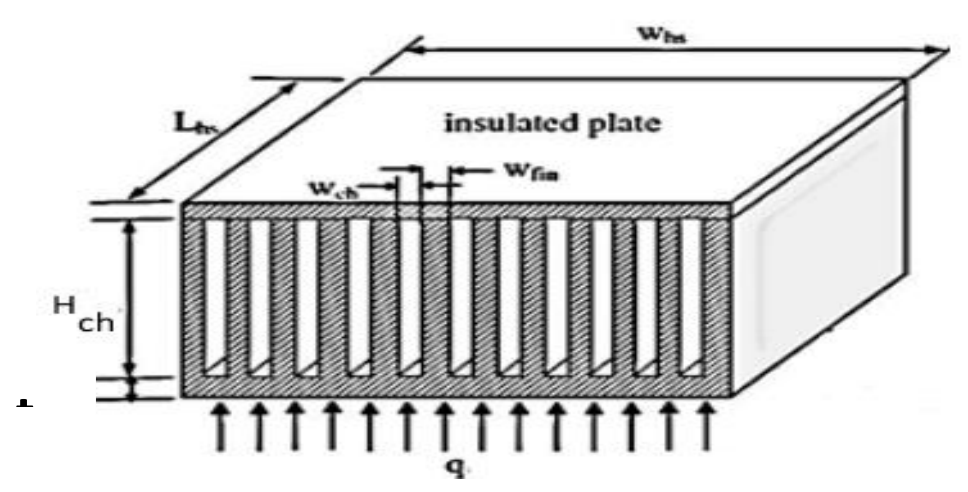

Figure 1. Schematic of the microchannel heat sink.

Table 1. Geometric parameters and thermal properties of heat sinks.

\begin{tabular}{lcc}
\hline Sl. No. & Geometric dimensions / thermal properties & Value \\
\hline 1 & Channel width $\left(\mathrm{W}_{\mathrm{ch}}\right)$ & $100[\mu \mathrm{m}]$ \\
2 & Fin thickness $\left(\mathrm{W}_{\mathrm{fin}}\right)$ & $100[\mu \mathrm{m}]$ \\
3 & Channel height $\left(\mathrm{H}_{\mathrm{ch}}\right)$ & $300[\mu \mathrm{m}]$ \\
4 & Number of channels $(\mathrm{n})$ & 60 \\
5 & Thermal conductivity $\left(\mathrm{k}_{\mathrm{s}}\right)$ & $238[\mathrm{~W} / \mathrm{m}-\mathrm{K}]$ \\
\hline
\end{tabular}




\section{Thermo-Physical Property Modelling of Nanofluids}

Four types of water-based nanofluids namely, $\mathrm{Al}_{2} \mathrm{O}_{3}, \mathrm{CuO}, \mathrm{TiO}_{2}$ and $\mathrm{SiC}$ are analysed. The Thermo-physical properties of water and nanoparticles at $298 \mathrm{~K}$ are listed in Table 2. The particle weight fraction of different nanofluids has been varied from $0 \%$ to $5 \%$. The thermophysical properties including density, viscosity, thermal conductivity and specific heat of different nanofluids have been calculated using Boungiorno [18], Bachelor [19], Hamilton-Crosser [20] and Boungiorno [18] models respectively. The mathematical models are shown in Eq. (1) to (4).

Table 2. Thermophysical properties of water and nanoparticles.

\begin{tabular}{lcccccc}
\hline $\begin{array}{l}\text { Sl. } \\
\text { No. }\end{array}$ & Properties & Water & $\mathrm{Al}_{2} \mathrm{O}_{3}$ & $\mathrm{CuO}$ & $\mathrm{TiO}_{2}$ & $\mathrm{SiC}$ \\
\hline 1 & Density $\left[\mathrm{kg} / \mathrm{m}^{3}\right]$ & 997.13 & 3970 & 6500 & 4156 & 3160 \\
2 & Viscosity $\left[\mathrm{N}-\mathrm{s} / \mathrm{m}^{2}\right]$ & $8.9 \times 10^{-4}$ & - & - & - & - \\
3 & Thermal conductivity [W/m- & 0.605 & 40 & 32.9 & 8.4 & 490 \\
K] & & & & & \\
4 & Specific heat $[\mathrm{J} / \mathrm{kg}-\mathrm{K}]$ & 4179 & 765 & 551 & 710 & 675 \\
\hline
\end{tabular}

$\rho_{n f}=(1-\phi) \rho_{b f}+\phi \rho_{n p}$

$\mu_{n f}=\left(1+2.5 \phi+6.2 \phi^{2}\right) \mu_{b f}$

$k_{n f}=\frac{k_{n p}+(n-1) k_{b f}-(n-1) \phi\left(k_{b f}-k_{n p}\right)}{k_{n p}+(n-1) k_{b f}+\phi\left(k_{b f}-k_{n p}\right)} k_{b f}$

Here, $n=3$ as spherical nanoparticles are considered.

$c_{n f}=\frac{(1-\phi) \rho_{b f} c_{b f}+\phi \rho_{n p} c_{n p}}{\rho_{n f}}$

\section{Modelling and Analysis of Microchannel Heat Sink}

The following assumptions are considered for analysing the microchannel heat sinks.

i. The nanofluids flow is considered to be steady, incompressible and laminar.

ii. A constant heat flux acting at the bottom of the test chip is considered.

iii. There is no heat loss from the surface.

iv. The thermophysical properties of nanofluids are invariant.

v. The body force effect is neglected.

Thermal resistance

In this present section, thermal performance of microchannel heat sink cooling with nanofluids has been analysed and compared with the performance of their base fluid 
water. The total thermal resistance per unit area is calculated using the 1-D thermal resistance model given in Eq. (5) [21].

$R_{\text {total }}=R_{\text {base }}+R_{\text {conv }}+R_{\text {bulk }}$

In Eq. (5), the first term, $R_{\text {base }}$ denotes the thermal resistance at the sink base, 2 nd term; $R_{\text {conv }}$ denotes thermal resistance due to convective heat transfer from microchannel heat sinks and last term, $R_{\text {bulk }}$ denotes the thermal resistance due to bulk flow of nanofluids. All three thermal resistances can be calculated from the Eq. (6), (7) and (15).

Base thermal resistance ( $R_{\text {base }}$ ) is estimated by dividing the base thickness with the thermal conductivity of heat sink material. The expression of $R_{\text {base }}$ is given in Eq. (6).

$$
R_{\text {base }}=\frac{t_{\text {base }}}{k_{s}}
$$

Where $t_{\text {base }}$ is the base thickness and $k_{s}$ is thermal conductivity of sink material. Convective thermal resistance from heat sink fins is adapted from reference[22].

$$
R_{c o n v}=\frac{\left(W_{c h}+W_{f i n}\right)}{\left(W_{c h} h_{n f}+2 h \eta_{f i n} H_{f i n}\right)}
$$

Where $\mathrm{h}_{\mathrm{nf}}$ is the heat transfer coefficient of nanofluids, that is estimated by using Eq. (8).

$$
h_{n f}=\frac{N u_{n f} k_{n f}}{d_{h}}
$$

$\mathrm{Nu}_{\mathrm{nf}}$ is Nusselt number for laminar flow in microchannel heat sink is estimated from Eq. (9) $[23]$.

$$
N u_{n f}=0.1165\left(\frac{d_{h}}{W_{c d}}\right)^{0.81}\left(\frac{H_{c h}}{W_{c h}}\right)^{-0.79} \operatorname{Re}_{n f}^{0.62} \operatorname{Pr}_{n f}^{0.33}
$$

$\mathrm{Re}_{\mathrm{nf}}$ and $\operatorname{Pr}_{\mathrm{nf}}$ are the dimensionless Reynolds's number and Prandtl number are defined and calculated from Eq. (10) and (11).

$$
\begin{aligned}
& \operatorname{Re}_{n f}=\frac{\rho_{n f} u_{n f} d_{h}}{\mu_{n f}} \\
& \operatorname{Pr}_{n f}=\frac{\mu_{n f} c_{n f}}{k_{n f}}
\end{aligned}
$$

$\mathrm{d}_{\mathrm{h}}$ is the hydraulic diameter of the microchannel. It is calculated as: 
$d_{h}=\frac{2\left(W_{c h} H_{c h}\right)}{\left(W_{c h}+H_{c h}\right)}$

$H_{f i n}$ and $\eta_{f i n}$ represents the fin height and fin efficiency respectively. The fin efficiency is given by Eq. (13).

$\eta_{f i n}=\frac{\tanh \left(m \times H_{c h}\right)}{m \times H_{c h}}$

Where, $m=\sqrt{\frac{2 h_{n f}}{k W_{c h}}}$

The thermal resistance due to the bulk motion of nanofluids is given by the Eq. (15) [22].

$R_{b u l k}=2 n\left(\frac{L_{c h}\left(W_{c h}+W_{f i n}\right)}{\rho_{n f} c_{n f} v_{n f}}\right)$

Where, $v_{n f}$ is the volumetric flow rate of nanofluids which is calculated by Eq. (16).

$v_{n f}=\frac{m_{n f}}{\rho_{n f}}$

Where, $\overrightarrow{m_{n f}}$ is the mass flow rate which is estimated by the Eq. (17).

$\dot{m}_{n f}=n u_{n f} \rho_{n f} A_{c h}$

$u_{n f}$ is the average flow velocity which is assumed as $0.5 \mathrm{~m} / \mathrm{s}$.

Thermal efficiency

The thermal efficiency of the present heat sink is calculated from the first law of thermodynamics as the ratio between heat removed by the heat sink to the energy input to the system as depicted in Eq. (18).

$\eta_{1 s t}=\frac{\dot{m}_{n f} c_{n f}\left(T_{n f, \text { out }}-T_{n f, \text { in }}\right)}{q}$

Here, $\mathrm{q}$ is the total heat input to the heat sink system which is taken as a constant value of $90 \mathrm{~W}$. The chip temperature is assumed to equal to $333 \mathrm{~K}$, and the outlet temperature of the nanofluids flow is provided by Eq. (19) [22]. 
$T_{\text {nf, out }}=T_{\text {chip }}-q\left(\frac{R_{\text {base }}+R_{\text {conv }}}{A_{\text {base }}}\right)$

Exergy loss

Exergy loss of a system refers to the loss of available work due to the irreversibility of a system. The exergy loss occurs when heat transfer occurs across a finite temperature difference. In microchannel cooling systems, heat transfer from channel wall to the coolant, power leakage and friction between the coolant and channel walls contributes to the exergy loss. The rate of exergy loss in the microchannel heat sinks in this present case is calculated by the expression given in Eq. (20)[24].

$$
X_{\text {loss }}=T_{o} \dot{m_{n f}} c_{n f} \ln \left(\frac{T_{n f, o u t}}{T_{n f, i n}}\right)
$$

Where, $T_{o}$ is the ambient or environmental temperature that is assumed to be $298 \mathrm{~K}$. The inlet temperature of nanofluid flow is also assumed equal to ambient temperature. The exergy loss due to the change of pressure is neglected as the nanofluids flow is assumed to be incompressible[25].

\section{Pumping power}

The pumping power for nanofluids is calculated as shown in Eq. (21).

$$
P_{\text {power }}=v_{n f} \Delta p
$$

Where $\Delta p$ denotes the pressure reduction during nanofluids flow. It is determined by the expression given in Eq. (22).

$$
\Delta p=f\left(\frac{L_{c h}}{d_{h}}\right)\left(\frac{\rho_{n f} u_{n f}^{2}}{2}\right)
$$

In Eq. (23), $f$ denotes the friction factor of the rectangular heat sinks, and for laminar flow, its value is given by Eq. (23) [26].

$$
f=\frac{56.9}{\mathrm{Re}_{n f}}
$$

\section{RESULT AND DISCUSSION}

\section{Influence of Nanoparticle Weight Fraction on Thermal Resistance}

The effect of nanoparticle concentration on thermal resistance is presented in Figure 2. The results show that thermal resistance decreases with the increase in weight fraction. The lowest thermal resistance was found to be $0.0001872 \mathrm{Km}^{2} / \mathrm{W}$ for $\mathrm{CuO}$ nanofluids. 
For $\mathrm{Al}_{2} \mathrm{O}_{3}, \mathrm{TiO}_{2}$ and $\mathrm{SiC}$ nanofluids the lowest thermal resistances were 0.0001899 $\mathrm{Km}^{2} / \mathrm{W}, 0.0001909 \mathrm{Km}^{2} / \mathrm{W}$ and $0.0001920 \mathrm{Km}^{2} / \mathrm{W}$ respectively. The reduction in thermal resistance as compared to water was observed 3.4\%, $2.01 \%, 1.49 \%$ and $0.92 \%$ for $\mathrm{CuO}$-water, $\mathrm{Al}_{2} \mathrm{O}_{3}$-water, $\mathrm{TiO}_{2}$-water and $\mathrm{SiC}$-water nanofluids respectively at5\% particle wt. fraction. When compared with the present data with previous studies, it is found that Khaleduzzaman et al. [17] reported lowest thermal resistance of 0.000179 $\mathrm{Kcm}^{2} / \mathrm{W}, 0.000181 \mathrm{Kcm}^{2} / \mathrm{W}$ and $0.000182 \mathrm{Kcm}^{2} / \mathrm{W}$ for $\mathrm{CuO}$-water, $\mathrm{A} 12 \mathrm{O} 3-\mathrm{W}$ ater and $\mathrm{TiO}_{2}$-Water nanofluids applied to a rectangular microchannel heat sink. Therefore, the present trend of decrease in thermal resistance is similar as published previously.

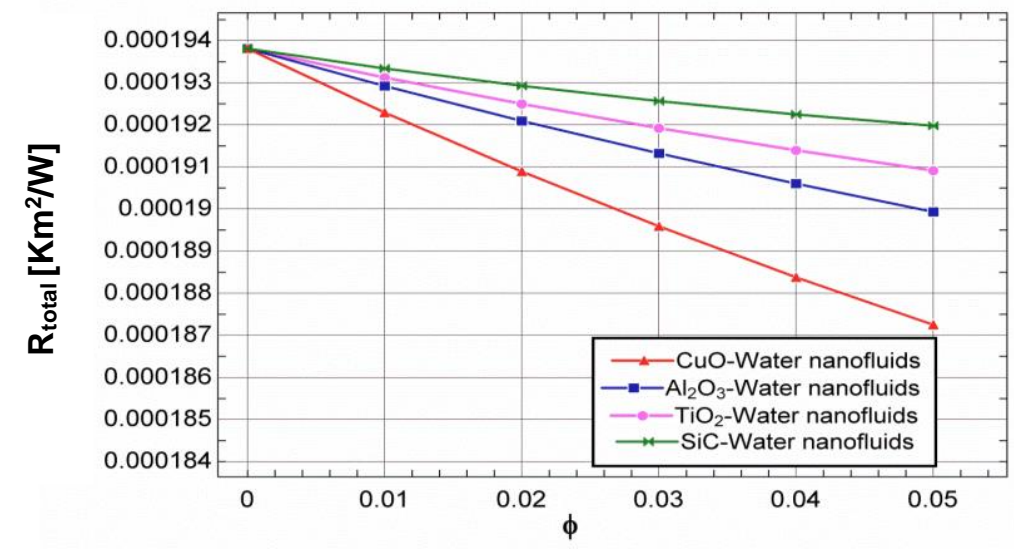

Figure 2. Variation of thermal resistance with nanoparticle weight fraction.

\section{Influence of Nanoparticle Weight Fraction on Thermal Efficiency}

Figure 3 shows the change in $1^{\text {st }}$ law efficiency as the nanoparticle weight fraction is varied. The $1^{\text {st }}$ law efficiency increased with nanoparticle addition in the base fluid. The maximum efficiency is $54.28 \%$ with $\mathrm{CuO}$-water nanofluids at $5 \%$ wt. fraction. The maximum efficiency values for $\mathrm{Al}_{2} \mathrm{O}_{3}$-water, $\mathrm{TiO} 2$ - water and $\mathrm{SiC}$-water nanofluids are $51.1 \%, 49.8 \%$ and $49.62 \%$ respectively. The water has a low efficiency of $42 \%$ as compared to nanofluids.

\section{Effect of Channel Number on Thermal Efficiency}

Figure 4 shows that when the number of microchannel increases the efficiency of the system increases. The number of the microchannel is directly proportional to the mass flow rate of nanofluids. Again, efficiency is directly related to mass flow rate. Therefore, with an increase in the number of channels in the heat sinks the mass flow rate increases and with the increase in mass flow the efficiency also increases. The maximum efficiency of $72.22 \%$ is obtainable when the number of channel increased to 70 using $\mathrm{CuO}$-water nanofluids at $2 \%$ wt. fraction. The water shows the maximum efficiency of $67.3 \%$ among the coolants. The efficiency of nanofluids is also influenced by specific heat capacity. Nanofluids with a higher value of heat capacity show low-efficiency enhancement. This attributes to the lowest efficiency enhancement in water, more efficiency enhancement in $\mathrm{SiC}$-water nanofluids than $\mathrm{TiO}_{2}$-water nanofluids and highest efficiency enhancement in CuO-water nanofluids. 


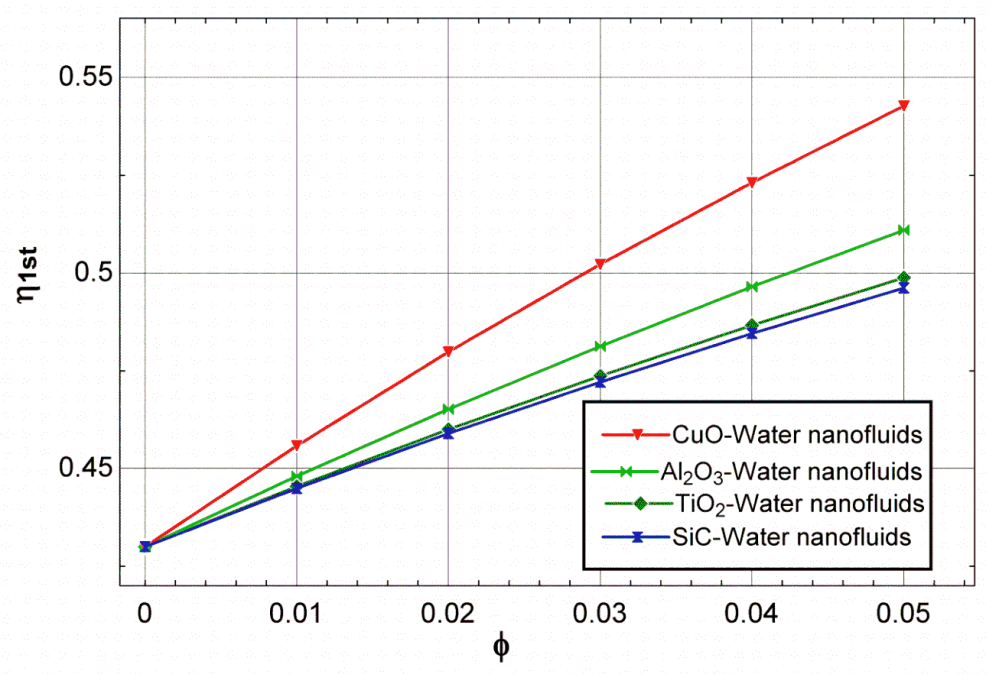

Figure 3. Effect of nanoparticle weight fraction on the efficiency of microchannel heat sinks.

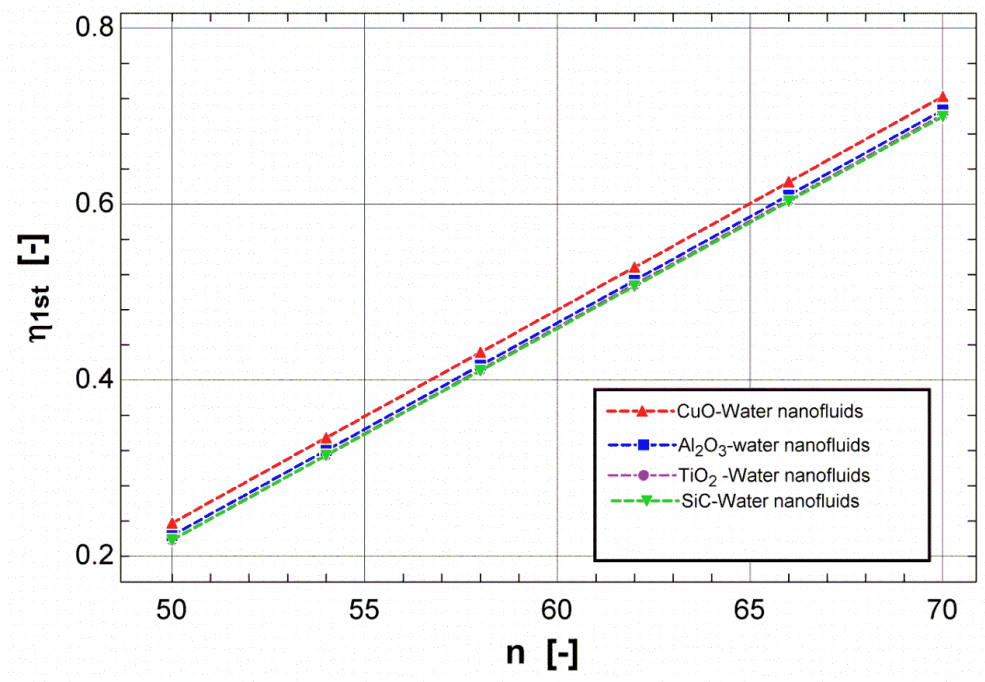

Figure 4. Nanofluid efficiency at number of microchannels in heat sinks.

\section{Effect of Base Thickness on Thermal Efficiency}

Figure 5 displays the effect base thickness on the efficiency of nanofluids. The base thickness was varied from $0.002 \mathrm{~m}$ to $0.006 \mathrm{~m}$. The efficiency was decreased along with the increase of base thickness ( $\mathrm{t}_{\text {base }}$ ). According to the Eq. (12), the base thermal resistance $\left(R_{\text {base }}\right)$ of microchannel is directly proportional to the base thickness. Therefore, $R_{\text {base }}$ increases as $\mathrm{t}_{\text {base }}$. Increase in $R_{\text {base }}$ value contributes to the total thermal resistance of microchannel heat sinks. As a result of this, the thermal efficiency decreases.

\section{Effect of Ambient Temperature on Thermal Efficiency}

Figure 6 illustrates the effect of ambient temperature on the efficiency of nanofluids at $2 \%$ wt. fraction. The efficiency decreases identically for all types of nanofluids with the 
gradual rise of ambient temperature. The minimum decline is observed for $\mathrm{CuO}$-water nanofluids and maximum for water.

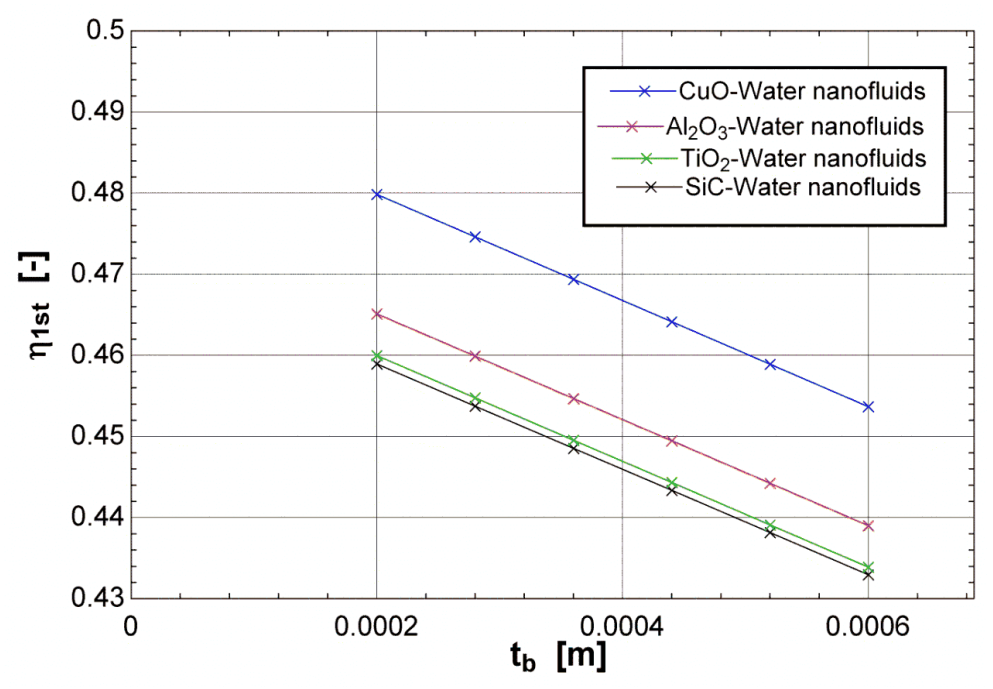

Figure 5. Effect of base thickness on efficiency.

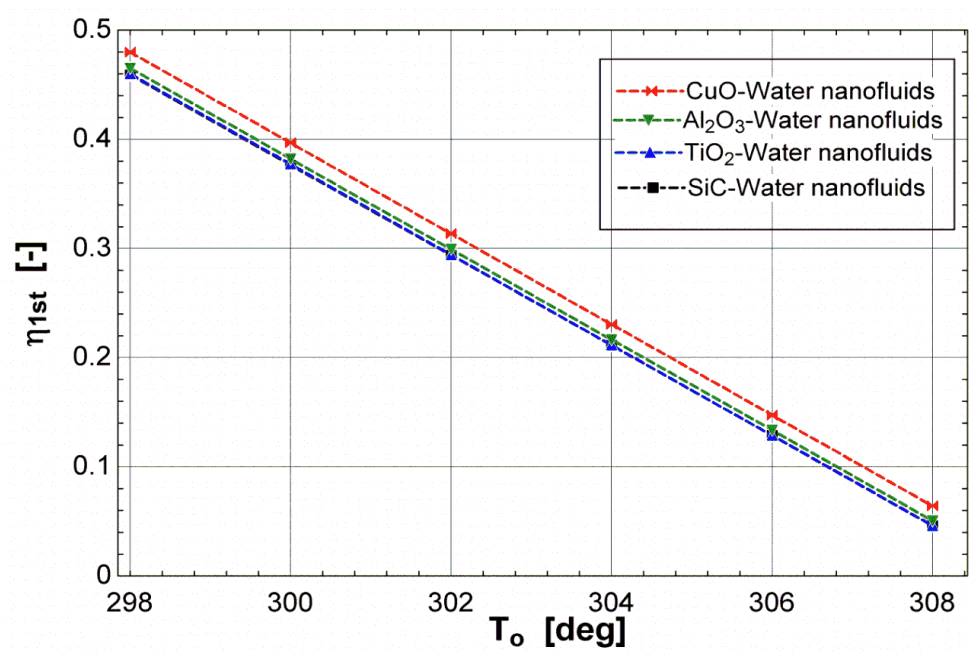

Figure 6. Effect of ambient temperature on the efficiency of heat sinks.

\section{Influence of Nanoparticle Weight Fraction on Exergy Loss}

The variation of exergy loss with nanoparticle weight fractions is plotted in Figure 7 . The exergy loss increases with the increase in particle concentration within the base fluid. The exergy loss is a function of specific heat capacity, mass flow rate and inlet-outlet temperature difference. Nanoparticle addition to base fluid causes an increase in mass flow rate and a decrease in specific heat capacity. However, the increase in mass flow rate is dominant over specific heat reduction. Therefore, exergy loss gradually increases with an increase in particle weight fraction within nanofluids. A maximum exergy loss of $47.8 \mathrm{~W}$ was found for $\mathrm{CuO}$-water nanofluids at5\% wt. fraction. The lowest exergy loss was found for $\mathrm{SiC}$-water nanofluids which is $43.77 \mathrm{~W}$ at $5 \%$ wt. fraction. The present trend of exergy loss is identical to the data presented in the literature[17, 24]. 


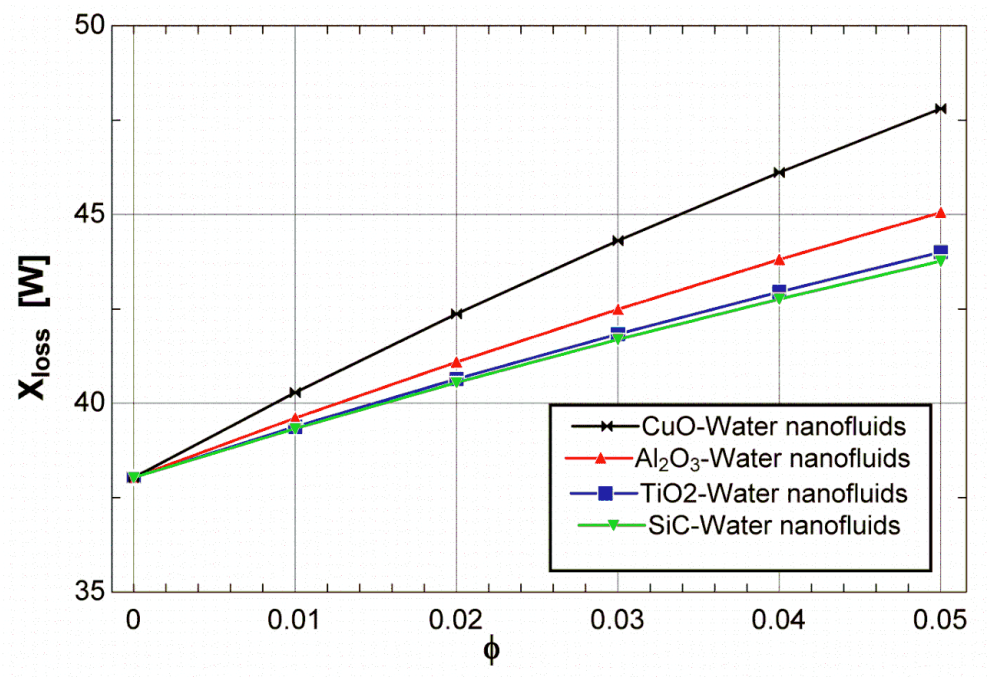

Figure 7. Variation of exergy loss with nanoparticle weight fraction.

\section{Effect of Channel Number on Exergy Loss}

The effect of variation of channel number on exergy loss of nanofluids flow at $2 \%$ wt. fraction was studied. According to Figure 8, the exergy loss gradually increased when the channel number increased. The increase in channel number endorsed a rapid rise in the mass flow rate of nanofluids. The increased mass flow facilitates the growth of exergy loss. The maximum exergy loss was found for $\mathrm{CuO}$ nanofluids when the channel number is increased to $70 \mathrm{~W}$. The minimum exergy loss was observed with $\mathrm{SiC}$-water nanofluids for a similar change of channel number.

\section{Influence of Base Thickness on Exergy Loss}

The base thickness of microchannel heat sinks plays a vital role in exergy loss. Figure 9 shows a graphical illustration of the change in exergy loss with the variation of microchannel base thickness. In the present study, the base thickness is varied from $0.0002 \mathrm{~m}$ to $0.0006 \mathrm{~m}$. The exergy loss is reduced with an increase in base thickness. The increase in base thickness contributes to base thermal resistance and the outlet temperature of nanofluids flow decrease, according to Eq. (19). As the outlet temperature of nanofluids is reduced; the exergy loss also reduced. The exergy loss for $\mathrm{CuO}$-Water nanofluids is more than other nanofluids, and it is $40.1 \mathrm{~W}$ at base thickness of $0.006 \mathrm{~m}$. The other exergy losses are 38.82, 38.38 and $38.29 \mathrm{~W}$ for $\mathrm{Al}_{2} \mathrm{O}_{3}-$ Water, $\mathrm{TiO}_{2}-\mathrm{W}$ ater and $\mathrm{SiC}$-Water nanofluids respectively at identical base thickness. Additionally, the change in exergy loss due to an increase in base thickness is the same for all nanofluids. 


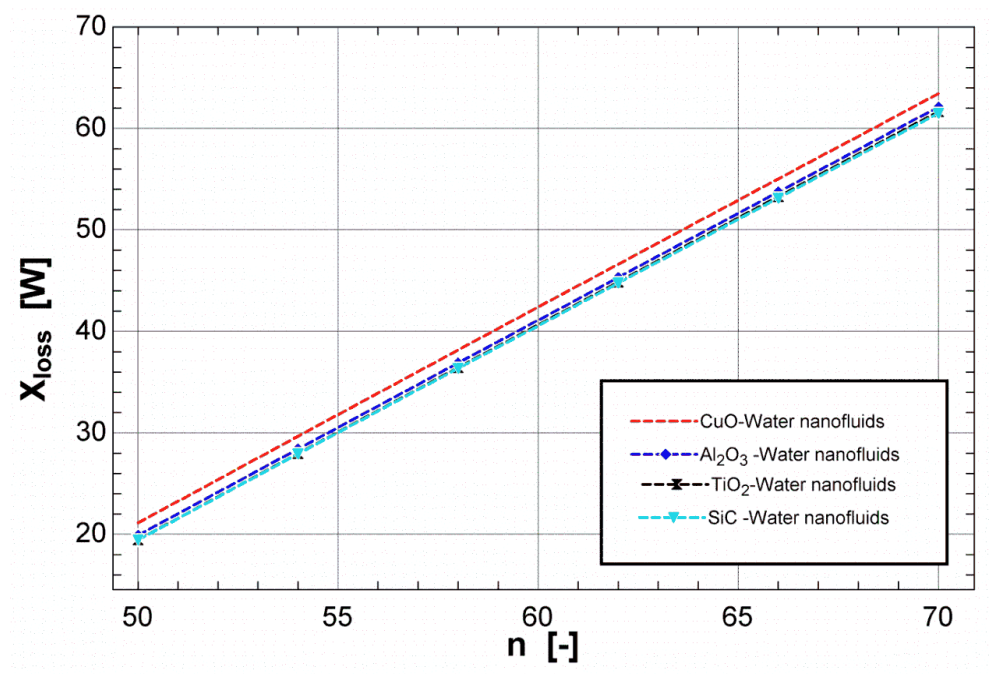

Figure 8. Variation of exergy loss with microchannel number.

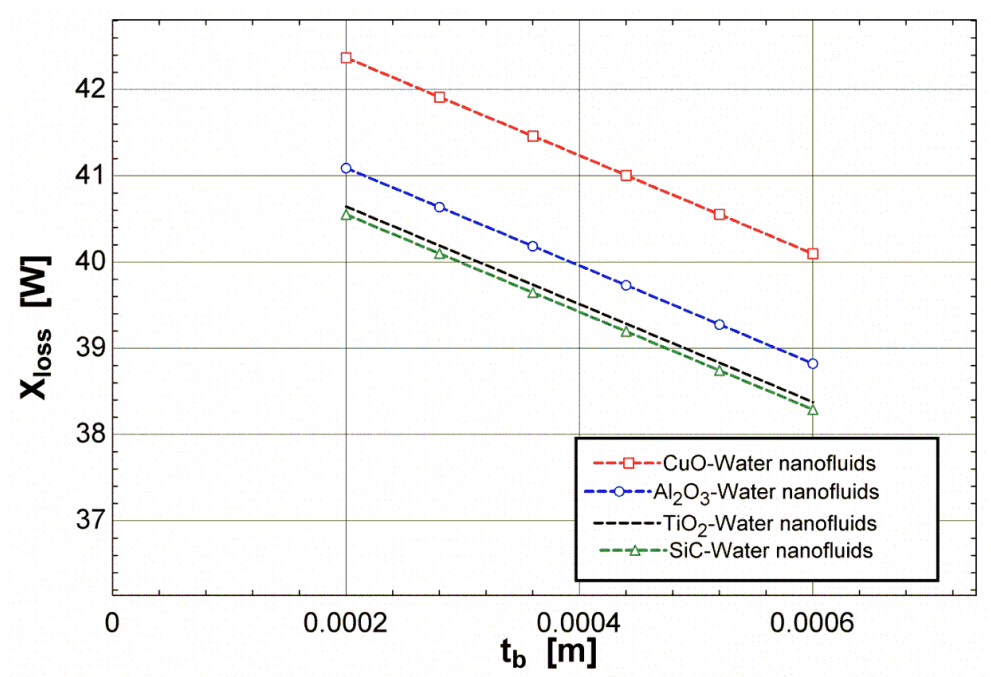

Figure 9. Effect of microchannel base thickness on exergy loss.

\section{Effect of Ambient Temperature on Exergy Loss}

Figure 10 presents the effect of ambient temperature on the exergy loss with different types of nanofluids. The ambient temperature was increased from $298 \mathrm{~K}$ to $308 \mathrm{~K}$, and the exergy loss decreased significantly for all types of nanofluids. According to Eq. (19), the exergy loss is a function of ambient temperature and inlet temperature of coolant flow. The coolant inlet temperature variation is more significant than ambient temperature deviation. Additionally, ambient temperature is considered here the same as coolant inlet temperature. Therefore, exergy loss decreased linearly with ambient temperature rise. 


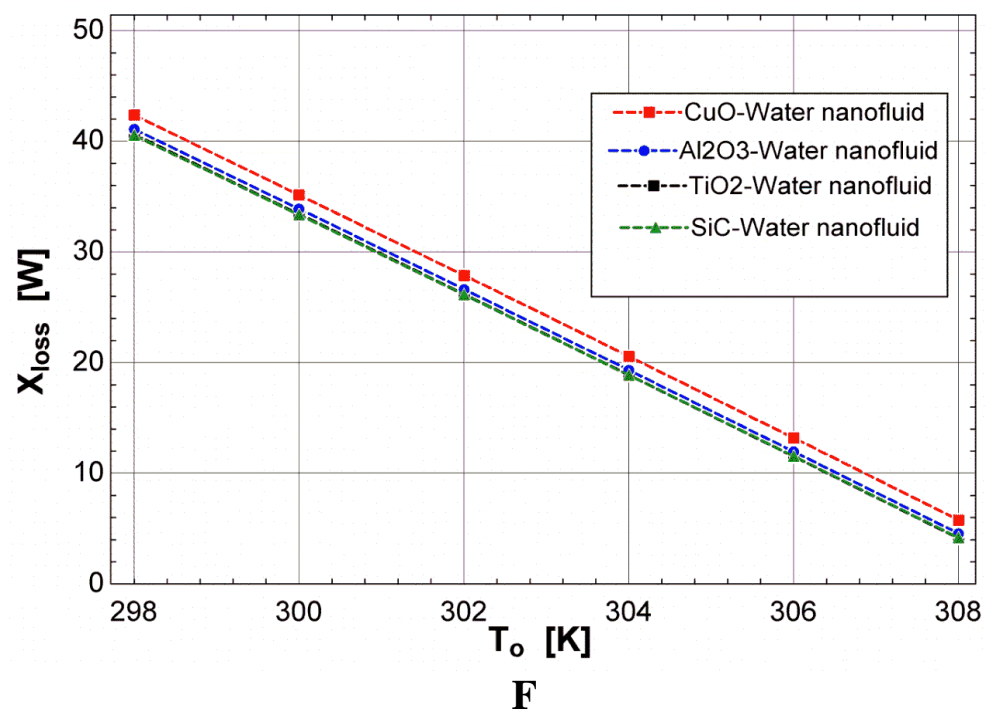

Figure 10. Effect of ambient temperature on exergy loss.

\section{Effect of Nanoparticle Weight Fraction on Friction Factor and Pumping Power}

Generally, the friction factor depends on Reynolds's number, density and volumetric flow rate of nanofluids. The inclusion of nanoparticles increases the density, volumetric flow rate and Reynolds number along with a significant decrease in friction factor. The effect of nanoparticle weight fractions on the friction factor is shown in Figure 11. For friction factor values, $\mathrm{CuO}$-water nanofluids show a rapid decrement with an increase in nanoparticle concentration while $\mathrm{Al}_{2} \mathrm{O}_{3}$-water and $\mathrm{TiO}_{2}$-water nanofluids show a gradual decrement. The friction factor of $\mathrm{SiC}$-water nanofluids shows an exception increase with the increase in nanoparticle weight fractions. This is because the friction factor is inversely related to the density of nanofluids. The sharp decline of fraction factor for $\mathrm{CuO}$-water nanofluids is due to the greater density of $\mathrm{CuO}$-water nanofluids than other nanofluids. The exceptional rise in $\mathrm{SiC}$-water nanofluids is because of the lower density value of $\mathrm{SiC}$-water nanofluids than other nanofluids. The decrease in friction factor naturally boosts the overall performance of heat sinks. However, reduction in friction factor brings minor changes in pressure reduction which has a very insignificant effect on the overall estimation and can be ignored [27].

The relation between pumping power and particle weight fraction at a constant inlet flow velocity of $0.5 \mathrm{~m} / \mathrm{s}$ is presented graphically in Figure 12. According to Eq. (21), pumping power depends upon density, mass flow rate and pressure reduction of nanofluids. Pumping power increases with nanoparticle concentration from $0-5 \%$ since the mass flow rate also rises with the increase of nanofluid concentration. However, the variation of pumping power rise is equal for all nanofluids. The minimum value of pumping power is $0.0101 \mathrm{~W}$ for water and a maximum of $0.0115 \mathrm{~W}$ for all nanofluids. Increase in mass flow rate and pressure reduction due to nanoparticle addition contribute to pumping power increment but at the same time density of nanofluids which is inversely related to pumping power, counterbalances the enhancement which attributes to the same pumping power for different nanofluids at same weight fractions. 


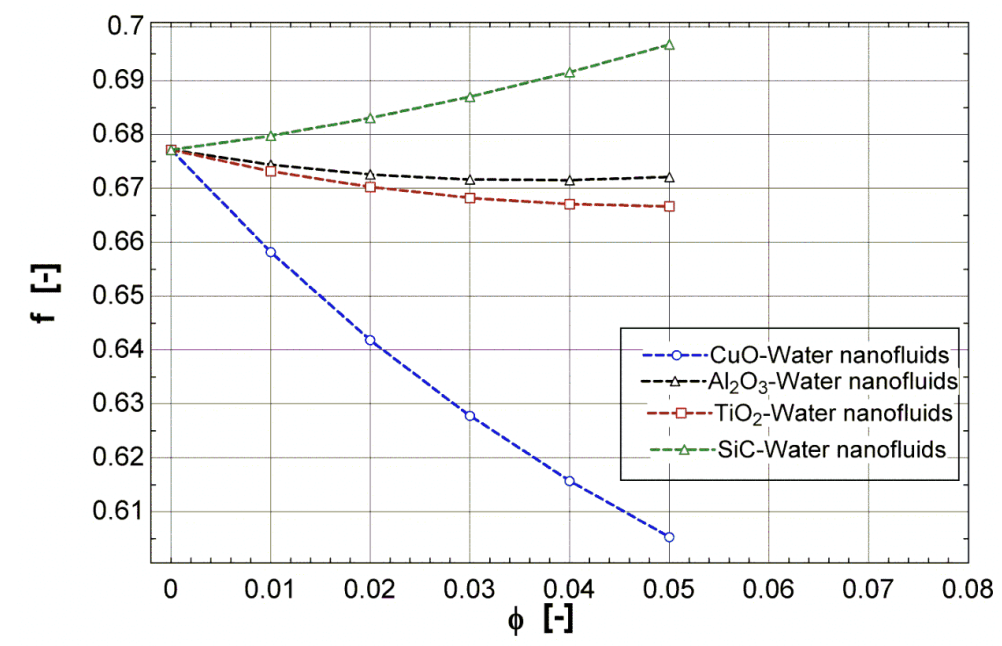

Figure 11. Variation of friction factor with nanoparticle concentration.

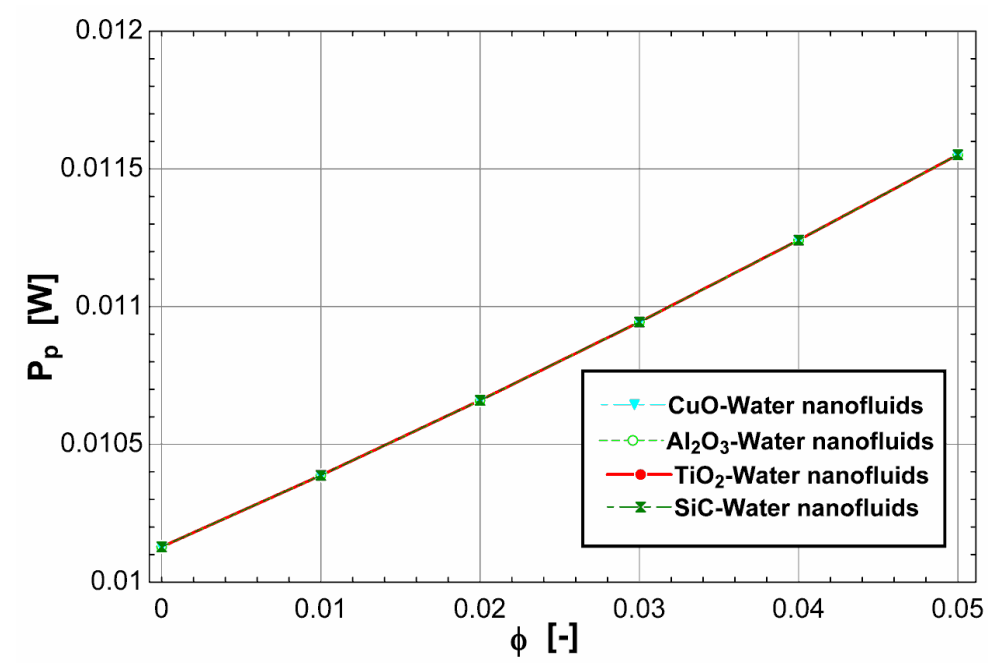

Figure 12. Variation of pumping power with nanoparticle concentration.

\section{Effect of Channel Number on Pumping Power}

Figure 13 shows the variation of pumping power concerning the number of microchannels in heat sinks. The mass flow rate of nanofluids increases with the increase in channel number at a fixed inlet flow of $0.5 \mathrm{~m} /$ and at a constant weight fraction of $2 \%$. Therefore, pumping power also increased to pump more nanofluids into microchannels. All nanofluids demand almost the same pumping power at each value of nanoparticle weight fractions as the flow and geometric parameters of microchannel assumed to be constant during analysis. 


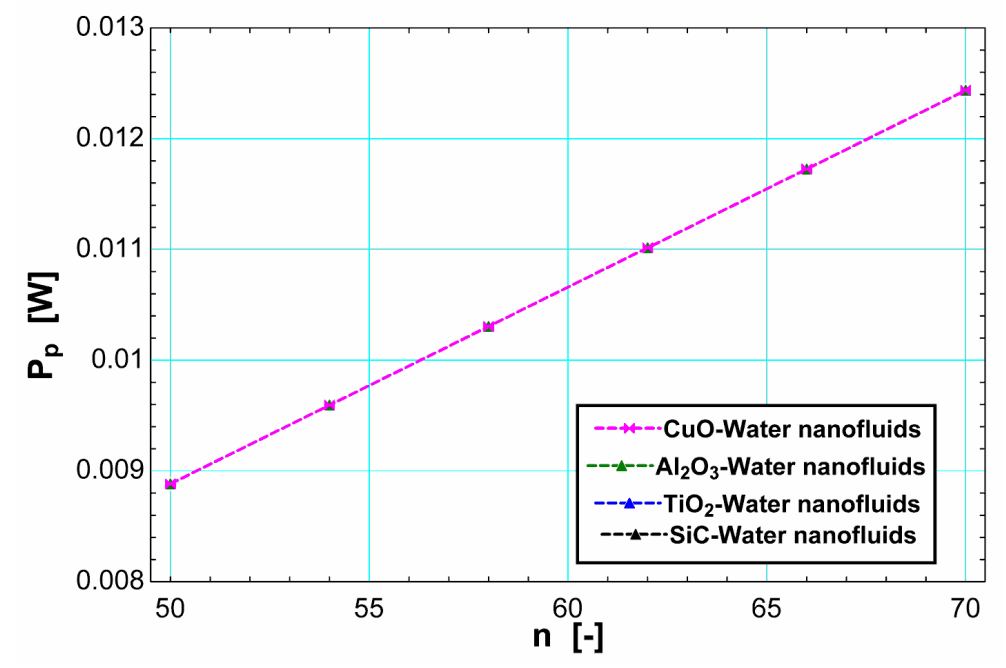

Figure 13. Variation of pumping power with number of channels.

\section{CONCLUSION}

In this present analysis, thermal resistance, thermal efficiency, exergy loss, friction factor and pumping power of microchannel heat sinks were investigated. Water-based $\mathrm{CuO}$, $\mathrm{Al}_{2} \mathrm{O}_{3}, \mathrm{TiO}_{2}$ and $\mathrm{SiC}$ nanofluids with weight fraction varying over the range of $0-5 \%$ were applied as a coolant and compared with water. The following conclusions are drawn.

i. The thermal resistance decreases with nanoparticle addition to base fluids.

ii. The efficiency of nanofluids can be improved by increasing nanoparticle concentration, a number of channels. Maximum improvement can be obtained by using $\mathrm{CuO}$-water nanofluids.

iii. The efficiency is influenced by base thickness. The efficiency decreases as the base thickness of heat sinks increases.

iv. The efficiency decreases with the rise of ambient temperature. The maximum exergy loss was shown by $\mathrm{CuO}$-water nanofluids and, minimum by $\mathrm{SiC}$-water nanofluids.

v. Exergy loss was varied with nanoparticle weight fractions. Exergy loss increases as nanoparticle weight fraction increases. The highest exergy loss can be obtained with $\mathrm{CuO}$-water nanofluids.

vi. The exergy loss reduced as the base thickness is increased.

vii. Exergy loss decreases with ambient temperature rise. A higher value of ambient temperature is favourable to reduce exergy loss from the microchannel heat sinks.

viii. Friction factor decreased for nanofluids with relatively higher viscosities, and the adverse is true for nanofluids of low viscosities. Friction factor of $\mathrm{CuO}$ in water nanofluids drops rapidly as compared to $\mathrm{Al}_{2} \mathrm{O}_{3}$ in water and $\mathrm{TiO}_{2}$ in water nanofluids. The $\mathrm{SiC}$ nanofluids show an adverse effect if it.

ix. The pumping power increased with nanoparticle inclusion, and it is found to be almost identical for different nanofluids at constant flow velocity. The highest demand for pumping power is provided by $\mathrm{CuO}$-water nanofluids and lowest demand of the same by water.

x. The pumping power increases as the number of channels of heat sinks increases.

The enhancement in thermal performance is indicated by the decrease in thermal resistance and friction factor with the improvement of energy efficiency due to 
nanoparticle addition to base fluids. Exergy loss and pumping power reduce thermal performance of heat sinks. Nanofluids display better performance than their base fluids; water. This widens the pathway to access the potential of nanofluids for an efficient cooling solution for electronic devices.

The $\mathrm{CuO}$-Water nanofluids show the highest performance. Hence, $\mathrm{CuO}$-water nanofluids are recommended over $\mathrm{Al}_{2} \mathrm{O}_{3}$-Water, $\mathrm{TiO}_{2}$-Water and $\mathrm{SiC}$-Water nanofluids. Nanofluids at low concentration are advisable for future use. This would result in the lowering of pumping power and saving of exergy with superior thermal performance.

\section{REFERENCES}

[1] Tuckerman DB, Pease RFW. High-performance heat sinking for VLSI. IEEE Electron device letters 1981; 2: 126-129.

[2] Choi SU, Eastman JA. Enhancing thermal conductivity of fluids with nanoparticles. Argonne National Lab., IL (United States), 1995.

[3] Chein R, Huang G. Analysis of microchannel heat sink performance using nanofluids. Applied Thermal Engineering 2005; 25: 3104-3114.

[4] Sohel MR, Khaleduzzaman SS, Saidur R, et al. An experimental investigation of heat transfer enhancement of a minichannel heat sink using $\mathrm{Al} 2 \mathrm{O} 3-\mathrm{H} 2 \mathrm{O}$ nanofluid. International Journal of Heat and Mass Transfer 2014; 74: 164-172.

[5] Abdollahi A, Mohammed HA, Vanaki SM, et al. Fluid flow and heat transfer of nanofluids in microchannel heat sink with V-type inlet/outlet arrangement. Alexandria Engineering Journal 2017; 56: 161-170.

[6] Farsad E, Abbasi SP, Zabihi MS, et al. Numerical simulation of heat transfer in a micro channel heat sinks using nanofluids. Heat and Mass Transfer 2011; 47: 479490.

[7] Bhattacharya P, Samanta AN, Chakraborty S. Numerical study of conjugate heat transfer in rectangular microchannel heat sink with $\mathrm{A} 12 \mathrm{O} 3 / \mathrm{H} 2 \mathrm{O}$ nanofluid. Heat and Mass Transfer 2009; 45: 1323-1333.

[8] Mohammed HA, Gunnasegaran P, Shuaib NH. Heat transfer in rectangular microchannels heat sink using nanofluids. International Communications in Heat and Mass Transfer 2010; 37: 1496-1503.

[9] Ho CJ, Wei LC, Li ZW. An experimental investigation of forced convective cooling performance of a microchannel heat sink with Al $2 \mathrm{O}$ 3/water nanofluid. Applied Thermal Engineering 2010; 30: 96-103.

[10] Azizi Z, Alamdari A, Malayeri MR. Convective heat transfer of $\mathrm{Cu}-$ water nanofluid in a cylindrical microchannel heat sink. Energy Conversion and Management 2015; 101: 515-524.

[11] Kalteh M, Abbassi A, Saffar-Avval M, et al. Experimental and numerical investigation of nanofluid forced convection inside a wide microchannel heat sink. Applied Thermal Engineering 2012; 36: 260-268.

[12] Naphon P, Khonseur O. Study on the convective heat transfer and pressure drop in the micro-channel heat sink. International Communications in Heat and Mass Transfer 2009; 36: 39-44.

[13] Wang XD, An B, Xu JL. Optimal geometric structure for nanofluid-cooled microchannel heat sink under various constraint conditions. Energy conversion and management 2013; 65: 528-538.

[14] Li J, Kleinstreuer C, Feng Y. Computational analysis of thermal performance and entropy generation of nanofluid flow in microchannels. In: Proceedings of ASME 
2012 3rd micro/nanoscale heat and mass transfer (MNHMT2012), track 2: nanofluids, session 2-3: theory, mechanisms, modeling and simulation of properties of nanofluids. 2012, pp. 135-144.

[15] Singh PK, Anoop KB, Sundararajan T, et al. Entropy generation due to flow and heat transfer in nanofluids. International Journal of Heat and Mass Transfer 2010; 53: 4757-4767.

[16] Li J, Kleinstreuer C. Entropy generation analysis for nanofluid flow in microchannels. Journal of Heat Transfer 2010; 132: 122401.

[17] Khaleduzzaman SS, Saidur R, Mahbubul IM, et al. Energy, exergy, and friction factor analysis of nanofluid as a coolant for electronics. Industrial \& Engineering Chemistry Research 2014; 53: 10512-10518.

[18] Buongiorno J. Convective transport in nanofluids. Journal of Heat Transfer 2006; 128: 240-250.

[19] Kumar PM, Kumar J, Suresh S. Review on nanofluid theoretical viscosity models. International Journal of Engineering Innovations and Research 2012; 1: 182-188.

[20] Hamilton RL, Crosser OK. Thermal conductivity of heterogeneous twocomponent systems. Industrial \& Engineering chemistry fundamentals 1962; 1 : 187-191.

[21] Kasten P, Zimmermann S, Tiwari M, et al. Hot water cooled heat sinks for efficient data center cooling: towards electronic cooling with high exergetic utility. Frontiers in Heat and Mass Transfer (FHMT) 2010; 1: 023006.

[22] Zimmermann S, Tiwari MK, Meijer I, et al. Hot water cooled electronics: exergy analysis and waste heat reuse feasibility. International Journal of Heat and Mass Transfer 2012; 55: 6391-6399.

[23] Peng XF, Peterson GP. Convective heat transfer and flow friction for water flow in microchannel structures. International Journal of Heat and Mass Transfer 1996; 39: 2599-2608.

[24] Pandey SD, Nema VK. Experimental analysis of heat transfer and friction factor of nanofluid as a coolant in a corrugated plate heat exchanger. Experimental Thermal and Fluid Science 2012; 38: 248-256.

[25] Gut JA, Fernandes R, Pinto JM, et al. Thermal model validation of plate heat exchangers with generalized configurations. Chemical Engineering Science 2004; 59: 4591-4600.

[26] Jung JY, Oh HS, Kwak HY. Forced convective heat transfer of nanofluids in microchannels. International Journal of Heat and Mass Transfer 2009; 52: 466472.

[27] Jung JY, Kwak HY. Fluid flow and heat transfer in microchannels with rectangular cross section. Heat and Mass Transfer 2008; 44: 1041-1049. 